\title{
The ultrasonographic diagnosis of cystic cervical lesions: a pictorial essay
}

\author{
Lavinia Manuela Lenghel1, Grigore Băciuțt2, Mihaela Băciuț² , Horaţiu Rotaru², Simion Bran², \\ Cristian Dinu ${ }^{2}$, Carolina Botar-Jid ${ }^{1}$, Mirela Gersak ${ }^{3}$, Sorin M. Dudea ${ }^{1}$
}

${ }^{1}$ Department of Radiology, "Iuliu Haţieganu” University of Medicine and Pharmacy, ${ }^{2}$ Department of Cranio-MaxilloFacial Surgery, "Iuliu Haţieganu” University of Medicine and Pharmacy, ${ }^{3}$ Radiology and Imaging Department, Emergency County Hospital, Cluj-Napoca, Romania

\begin{abstract}
The importance of ultrasonographic (US) examination in the evaluation of the superficial structures of the head and neck region is increasing due to the widespread availability of modern equipment (such as high-frequency transducers) and modern techniques. In the case of a cervical lesion, ultrasound is usually the first imaging method used to assess the changes. First of all, US is capable of differentiating between cystic and solid structures, and based on the US appearance correlated with the the age of the patient, location and growing pattern, the appropriate diagnosis is possible with a high accuracy. The aim of the present paper is to describe the US features of the most common cystic lesions encountered in the head and neck region.

Keywords: ultrasonography, cyst, congenital, head and neck region
\end{abstract}

\section{Introduction}

Ultrasonography (US) represents the first imaging method used for the evaluation of nodular lesions in the head and neck. For achieving the appropriate diagnosis, the examiner should have very good knowledge regarding the anatomy, the clinical status of the patient and the ability to recognize pathological changes $[1,2]$.

Cystic lesions are frequently encountered in the cervical region, being divided into two separate categories: congenital and acquired. The data obtained at the clinical exam and the age of the patients narrow the differential diagnosis [3]. The congenital cystic masses are characteristic for pediatric patients and young adults. On the other hand, a newly appeared cystic lesion encountered in an adult, should be regarded as suspicious for metastatic node with necrosis [4].

Received 19.03.2016 Accepted 29.03.2016

Med Ultrason

2016, Vol. 18, No 2, 240-246

Corresponding author: Cristian Dinu

Department of Cranio-Maxillo-Facial Surgery, Iuliu Haţieganu" University of Medicine and harmacy, Cluj-Napoca

33 Calea Moților, 400001 Cluj-Napoca, Romania E-mail: dinu_christian@yahoo.com
Harnsberger et al [5] describe a more complex classification of cervical cystic lesions, according to the age and the frequency of the findings, as shown in table I.

Table I. The classification of cervical cystic lesions, according to the age and the frequency of the findings [5, addapted].

\begin{tabular}{|c|c|c|}
\hline Frequency & Pediatric age & Adult age \\
\hline Common & $\begin{array}{l}\text { Infected lymph nodes } \\
\text { (abcess) } \\
\text { Cervical abcesses } \\
\text { Thyroglossal duct } \\
\text { cyst } \\
\text { Lymphatic malfor- } \\
\text { mations } \\
\text { Ranula } \\
\text { Second branchial } \\
\text { cleft cyst }\end{array}$ & $\begin{array}{l}\text { Metastatic necrotic } \\
\text { nodes } \\
\text { Cervical abcesses } \\
\text { Infected lymph nodes } \\
\text { (abcess) } \\
\text { Lymphatic malfor- } \\
\text { mations } \\
\text { Ranula }\end{array}$ \\
\hline Less common & $\begin{array}{l}\text { First branchial cleft } \\
\text { cyst } \\
\text { Thymic cyst }\end{array}$ & $\begin{array}{l}\text { Thyroglossal duct } \\
\text { cyst } \\
\text { Second branchial } \\
\text { cleft cyst } \\
\text { Lymphoma }\end{array}$ \\
\hline $\begin{array}{l}\text { Rare but } \\
\text { important }\end{array}$ & $\begin{array}{l}\text { Dermoid/epidermoid } \\
\text { cyst } \\
\text { Teratoma }\end{array}$ & $\begin{array}{l}\text { Cystic schwannoma } \\
\text { Zenker diverticulum }\end{array}$ \\
\hline
\end{tabular}




\section{Congenital cervical cystic masses}

Thyroglossal duct cyst represents the most common congenital lesions of the cervical region, representing approximately $90 \%$ of nonodontogenic congenital cysts $[6,7]$. The diagnosis is relatively easy, pointed by the presence of a cystic mass located on the anterior midline compartment of the neck [8]. The thyroglossal duct is a tubular structure that connects the thyroid gland with the tongue that is closing in the 8th-10th gestational week. The superior end of the duct is foramen cecum, and the inferior end will become the pyramidal lobe of the thyroid gland [9]. Thyroglossal duct cysts appear due to a persistence of the duct [10]. The duct is passing through the hyoid bone, these two structures being closely associated during ontogenesis [11]. In consequence the thyroglossal duct cyst will be found around the hyoid level (20-25\% suprahyoid, $15-50 \%$ hyoid, $25-65 \%$ infrahyoid), usually on the midline or no more than $2 \mathrm{~cm}$ away from the midline $[9,12]$ (fig 1) and very rarely in the floor of the mouth [13].

The diagnosis is frequently established during childhood or young adulthood, but still in $15 \%$ of cases the thyroglossal duct cysts are diagnosed after the age of 50 [9].

The US characteristic appearance of the thyroglossal duct cyst is a homogeneous, anechoic, thin walled lesion, with posterior enhancement, but this pattern is seen only in $42 \%$ of the cases $[4,8]$. Quite often these cysts may contain some internal debris or have a very heterogeneous appearance (fig 2), probably due to infection or hemorrhage. Sometimes the appearance may mimic a solid structure, more probably due to the proteinaceous content (fig 3) $[3,4,14,15]$.

The acoustic enhancement is often difficult to depict due to gas in the neighboring pharynx and larynx. The cystic lesion may have thick walls (especially when infected). Usually the lesion can be compressed with the transducer and also displaced [4].

Identification of a solid component within the cyst raises the suspicion of a thyroid carcinoma, which may appear in $1 \%$ of the cases, $80 \%$ being of the papillary type $[4,16]$. The assessment of the thyroid gland is important because, very rarely, these cysts may contain the only functioning thyroid tissue [4].

\section{The branchial cleft cysts}

The term cyst is used when no communication is present between the inner pharyngeal mucosa and the outer cervical skin. Sinus anomalies have one communication open (at the pharyngeal mucosa or the skin) and mesenchymal tissue at the other end. The term fistula is used when both openings are present [17].

First branchial cleft cyst represents 5-8\% of all branchial anomalies, more frequently encountered in middle-age females. They develop between the external auditory ca-
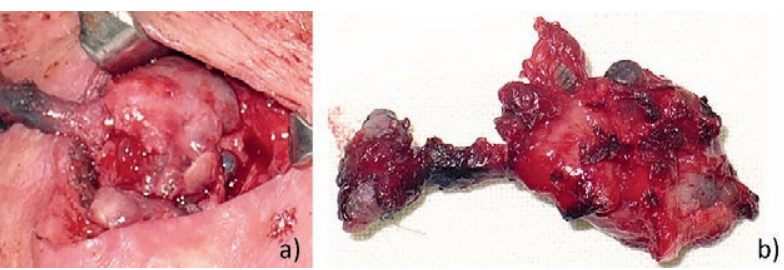

Fig 1. A 42 year old male patient with a thyroglossal duct cyst: a) photograph during the surgical resection of the thyroglossal duct cyst; b) photograph of the surgical specimen

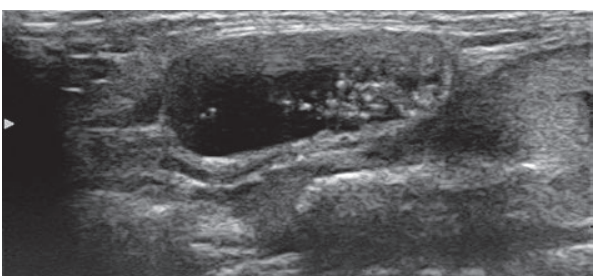

Fig 2. A 32 year old female, with a painful swelling at the infrahyoid level, in the right side. The grey-scale ultrasound reveals an inhomogeneous cystic structure with thick walls. The histological report confirmed a thyroglossal duct cyst.

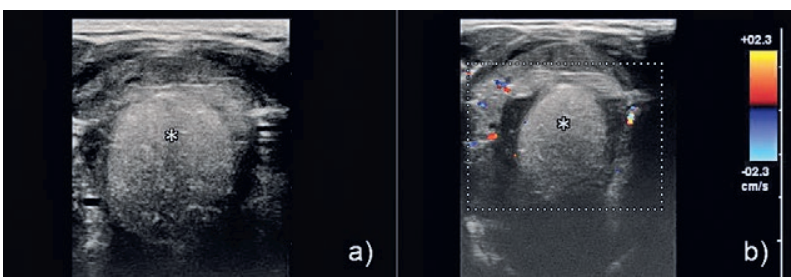

Fig 3. A 10 year old female, with a slowly growing mass in the floor of the mouth, in the midline: a) grey scale exam discover a pseudosolid, relatively homogenous structure; b) Doppler US show no vessels in the lesion. The histological report confirmed a thyroglossal duct cyst.

nal, the parotid and submandibular spaces [8]. Clinically, these cysts usually manifest as recurrent abscesses or inflammation around the ear or at the mandibular angle. Other symptoms may appear, such as otorheea (in case of communication between the cyst and the external auditory canal) and facial nerve paralysis $[8,16]$. Work [18] described two types: type I: derives from the ectoderm, being located medially to the concha of the ear and type II: derives from the ectoderm and mesoderm, containing skin appendages (sebaceous and sweat glands, hair follicles); it affects the external auditory canal and the cartilaginous pinna and includes very often parotid lesions [18,19].

The second branchial cleft cyst represents $95 \%$ of all branchial anomalies and occurs between 10-40 years of age, with no predilection for gender [8]. Bailey [20] classifies these anomalies in four types: type I - located superficially, along the anterior margin of the sternocleidomastoid muscle and deep to the platysma muscle; type II - the most 
common, along the anterior margin of the sternocleidomastoid muscle, lateral to the carotid space and posterior to the submandibular gland; type III - extends between the internal and external carotid arteries, lateral to the pharyngeal wall; type IV - situated in the pharyngeal mucosa.

Clinically these cysts are painless, fluctuant, slowgrowing lateral neck masses. If infected, pain and tenderness may appear [8].

The third branchial cleft cyst is rare (3\%) and is located in the posterior cervical space [8].

The fourth branchial cleft cyst represents approximately $1 \%$ of the cases. It extends from the pyriform sinus, passes through the thyrohyoid membrane and descends along the tracheoesophageal groove [3].

On US examination uninfected cysts are well defined, with thin walls, anechoic, homogenous, with acoustic enhancement (fig 4).

Sometimes a pseudosolid appearance may be found, due to the proteinaceous content [21].

If infection occurs, the walls become thicker, irregular, the cyst is ill-defined and the internal structure is inhomogeneous, with debris and septa (fig 5-7) [21].

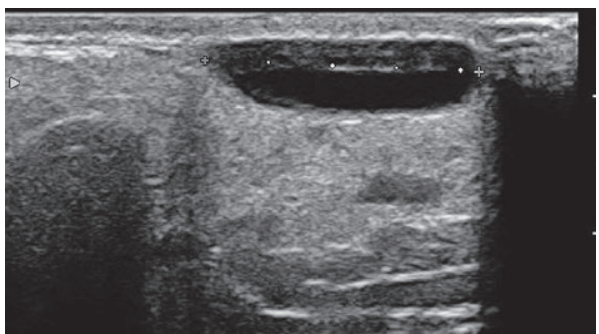

Fig 4. A 36 year old female with a discrete swelling, painless, in the left parotidian space. The grey-scale US reveal an anechoic, well delineated, thin walled lesion, with posterior acoustic enhancement, located in the parotid gland, in the superficial lobe. The histological report confirmed a first cleft branchial cyst.

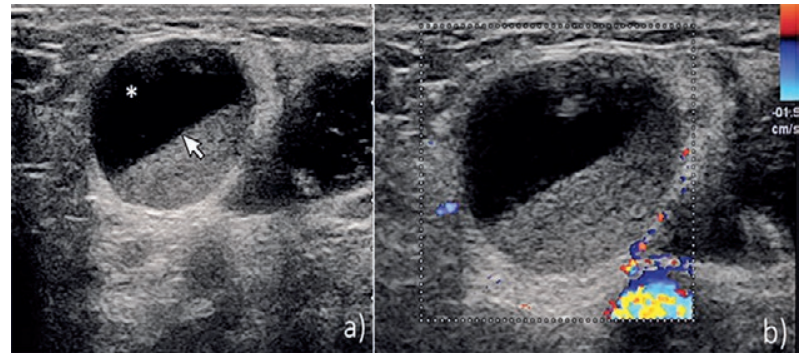

Fig 5. A 43 year old male patient, with a sudden and painful mass in the left lateral neck, after a minor trauma: a) grey-scale US found a inhomogeneous cystic structure, well delineated, with fluid-fluid levels; b) Doppler US showed no vascularization inside the lesion. The histological report confirmed a second cleft branchial cyst, with internal hemorrhage.
These features can mimic cystic nodal metastasis [22]. The diagnosis between these two entities is challenging, both for the clinician and the radiologist. In the adult population, cystic neck masses should be considered primarily as metastatic nodes until the benignity is proven [23, 24].

Lymphangiomas are congenital abnormalities arising from the lymphatic system, with an infiltrative pattern, representing around 5-6\% of all benign global lesions in pediatric patients. Most of them (80-90\%) are detected in the first 2 years of life $[8,9]$. There are three major theories proposed in order to explain the development of lymphangiomas: the failure of the primordial lymphatic sac to drain into the veins, abnormal sequestration of lymphatic tissue, and abnormal budding of the lymphatics [9].

There are four histological types of these anomalies: cystic hygroma (lymphangioma - the most common), cavernous lymphangioma, capillary (simple) lymphangioma and vasculolymphatic malformation (lymphangiohemangioma) [9].

Lymphangiomas are most frequently present in the cervical region $(75 \%)$, especially in the posterior neck and oral cavity in children and in the sublingual, subman-

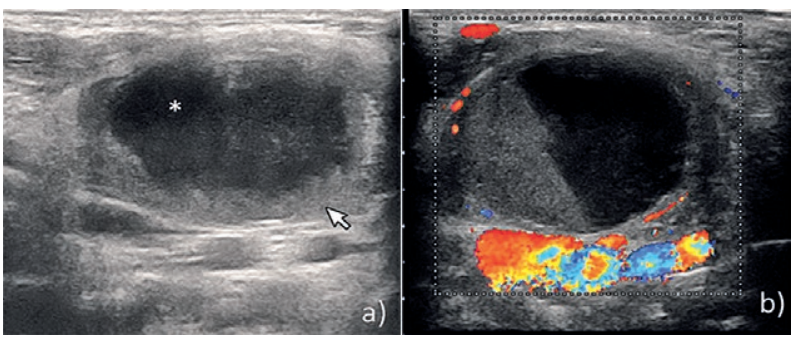

Fig 6. A 10 year old female patient, with a sudden and painful mass developed in the right lateral neck: a) grey-scale US found a inhomogeneous cystic structure, ill-defined, thick walls, with internal debris and a partially fluid-fluid appearance; b) Doppler US showed no vascularization inside the lesion and a few vessels in the peripheral part. After the treatment with antibiotics, the lesion reduced in size and the histological report confirmed a second cleft branchial cyst.

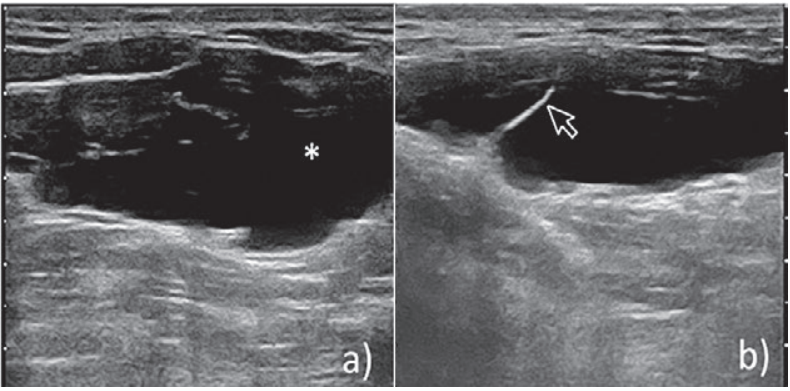

Fig 7. A 38 year old male patient, with a very large, fluctuant, slow-growing mass located in the left posterior cervical space. The grey-scale US found a inhomogeneous anechoic structure, well defined, thin walls, with internal septa. The histological report confirmed a third cleft branchial cyst. 


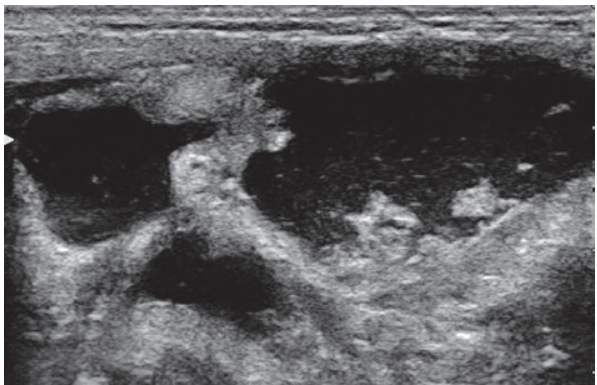

Fig 8. A 1 year and 3 month old male patient with a mass in the left parotidian space. The grey-scale US reveals a multiloculated cystic structure, with impure fluid content. The diagnosis was a cystic lymphangioma.

dibular and parotid spaces in adults. Uncommonly, they are also described in other sites, such as the mediastinum $(5 \%)$, axilla (20\%), abdominal cavity (in the colon, liver and spleen), retroperitoneum (in the kidneys), scrotum and, very rarely, in the skeletal system $[25,26]$.

The patient present with a painless, soft tissue cervical mass. After trauma or when hemorrhage or infection occurs, usually a sudden enlargement of the mass is noticed. More rarely, symptoms such as facial nerve paralysis, dysphagia, or feeding difficulties have been described [27-29]. In very rare cases, if the mass is very large, an extension and compression of the airways may appear, leading to the death of the patient [27].

The US examination reveals a multiloculated cystic lesion, often extending across several anatomic compartments, with septa of different thickness (fig 8). If hemorrhage is associated, then fluid-fluid levels are seen [3].

Teratomas, epidermoid cysts and dermoid cysts

The term teratoma defines a lesion that is containing multiple tissues not normally found in the region where these neoplasms occur. Teratomas are very rare and approximately $10 \%$ of them affect the cervical area [30]. Dermoid cysts represent the most common form of teratomas. They contain squamous cell epithelium, a fibrous wall and skin appendages (such as sebaceous glands, hair follicles). By comparison, the epidermoid cyst contains only squamous cell epithelium with a fibrous wall and teratoid cyst tissue derived from all three germinal layers [31].

Dermoid cysts most commonly involve the orbit, followed by the oral cavity (especially the floor of the mouth, but may also appear in the lips, tongue or buccal mucosa) and the nasal region [32]. Clinically these lesions appear as painless slow-growing masses. During pregnancy they may rapidly enlarge [9]. At US, the epidermoid cyst usually appears as a simple cystic structure, but pseudosolid appearance is also possible. Meanwhile,

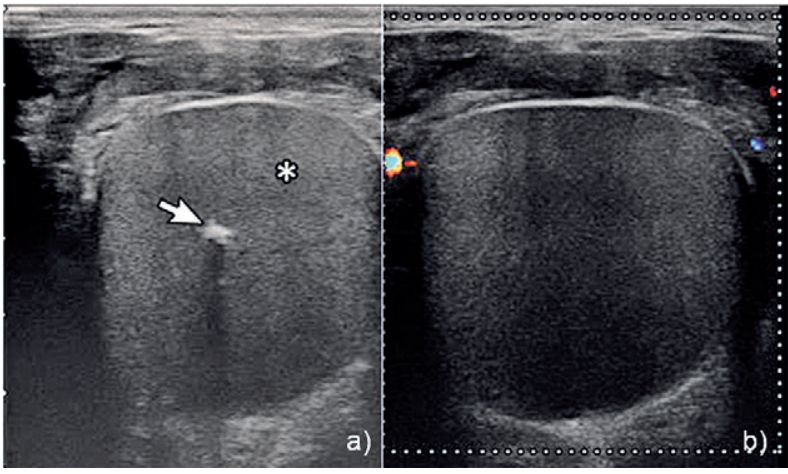

Fig 9. A 21 year old male with a slow-growing mass in the floor of the mouth: a) grey scale US showed an echoic structure, well defined, thin walls, regular border, with a small foci of calcification (hyperechoic, with acoustic shadow); b) Doppler US proved the lack of vascular signal inside the lesion. The US diagnosis based on the findings and location was a dermoid cyst, confirmed by the histological report.

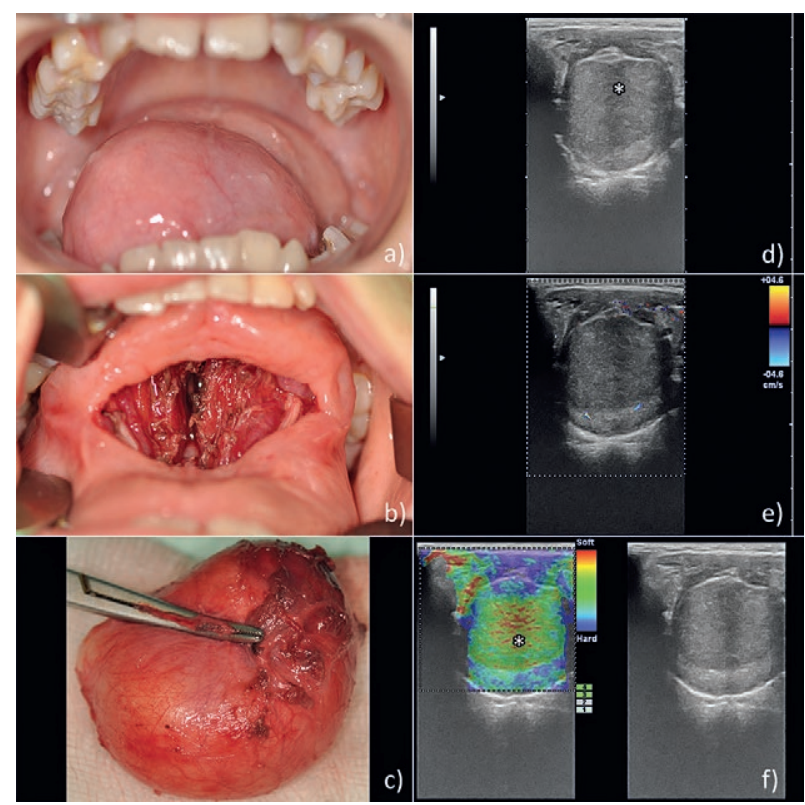

Fig 10. A 10 year old female patient with a slow-growing mass in the floor of the mouth: a) photograph shows the mass in the floor of the mouth; b) a photograph to the floor of the mouth after the surgical extraction of the lesion; c) photograph of the surgical specimen; d) grey scale US showed an pseudosolid structure well defined, thin walls, regular border; e) Doppler US proved the lack of vascular signal inside the lesion; f) at elastography the structure was soft. The US diagnosis based on the findings and location was a dermoid cyst, confirmed by the histological report.

the dermoid cyst, due to the presence fat, fluid and calcification (represented by the osseo-dental structures), produces more commonly a mixed appearance (fig 9,10). Sometimes, the dermoid cysts are difficult to differentiate from thyroglossal duct cysts $[4,21]$. 


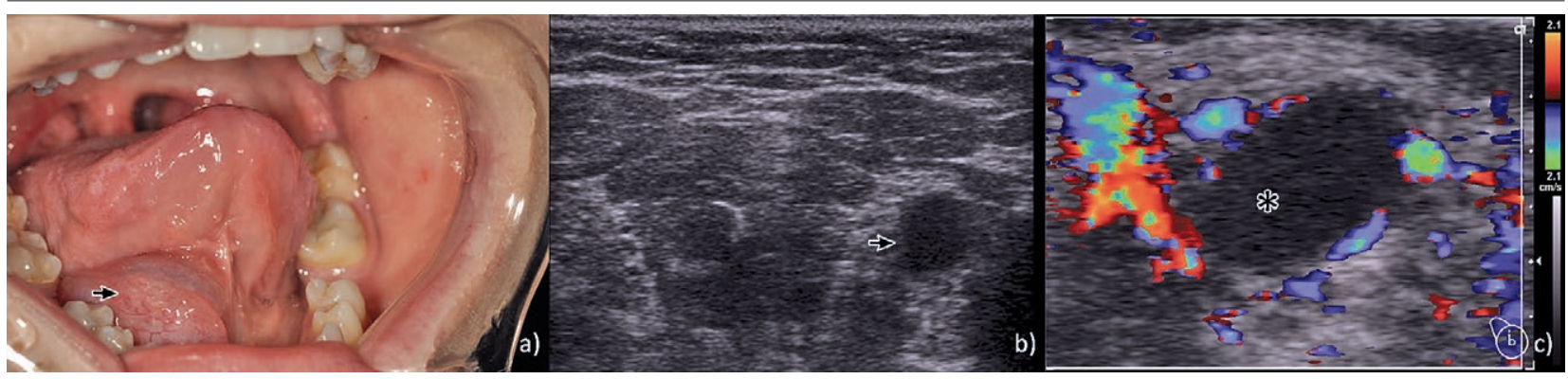

Fig 11. a) photograph of a ranula in the right sublingual space; b) another patient with a anechoic well defined cystic structure in the left sublingual gland; c) the same patient as in b, with no vascular signal inside the lesion detected at Doppler examination. The US diagnosis was simple ranula.

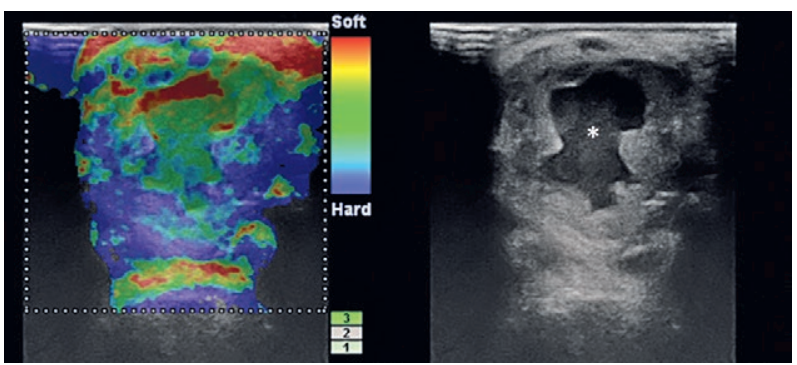

Fig 12. A 76 year old male patient with previous squamous cell carcinoma in the right ear, presenting with a mass in the right parotid space. Grey-scale and elastographic appearance showed a metastatic lymphadenopathy, with central necrosis, in the right parotid gland.

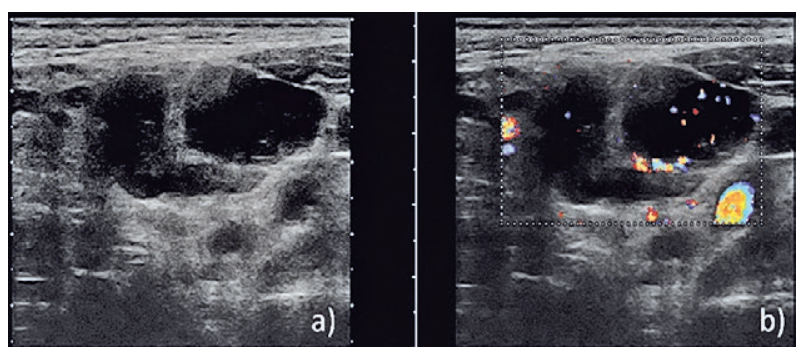

Fig 13. a) Grey scale US reveal a necrotic lymphomatous node in a male patient with Hodgkin lymphoma; b) Doppler US confirms the lack of the vascular signal in the necrotic areas.

\section{Acquired cervical cystic masses}

Ranula is a cystic lesion that occurs in the sublingual gland, secondary to the obstruction of the sublingual duct. They are divided into simple ranulas (located on the sublingual space) and "plunging" or "diving" ranulas (located in the sublingual and submandibular space, appearing secondary to the rupture of the wall of the simple ranula) [4].

On US ranula appears as an anechoic, cystic lesion, unilocular, avascular, well delineated by thin walls (fig $11)$; in infections, the walls may become thicker [3].

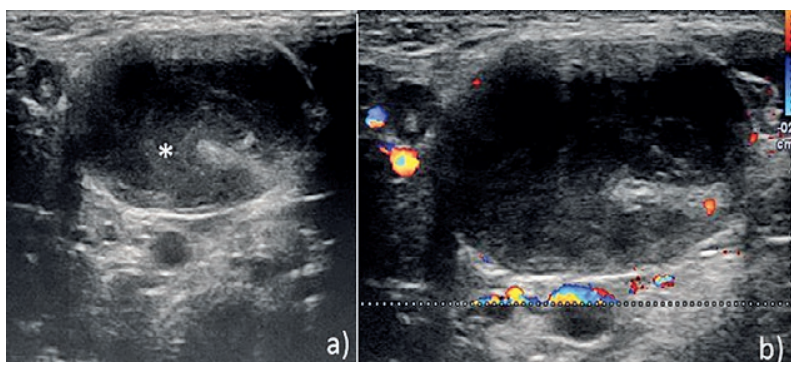

Fig 14. A 7 year old male patient with a painful mass in the right neck, with night fever: a) grey scale US reveal a lymphadenopathy with necrosis; b) Doppler US shows no vascularity in the necrotic node. The etiology of the changes proved to be tuberculous.

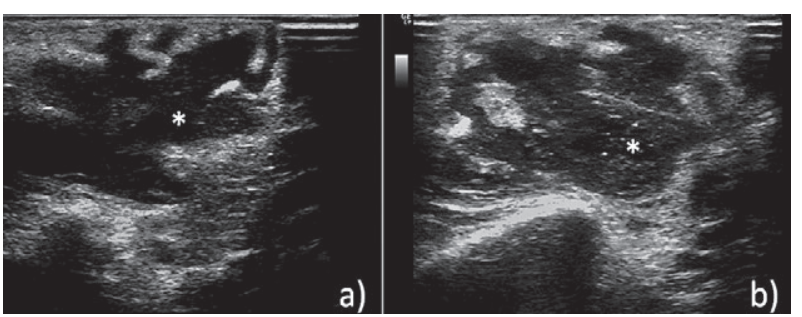

Fig 15. A 2 year old female patient with a tender and painful swelling of the right parotid space. Grey scale US ( $a$ and b) reveals an abcess (developed in a preexisting lymph node) in the right parotid gland, surgically drained under US guidance.

\section{Necrotic nodal masses}

Cystic (liquefaction) necrosis appears as a fluid area within an enlarged lymph node. It is highly suggestive for malignancy in cases of known primary squamous cells [33] or papillary carcinoma [34, 35] (fig 12).

Very rarely, lymphomatous lymph nodes may present areas of cystic necrosis, more often encountered after treatment or in advanced stages [36] (fig 13).

Intranodal liquefaction can also be identified in benign conditions, such as tuberculosis (fig 14) or abscess formation (fig 15, 16) [37]. 


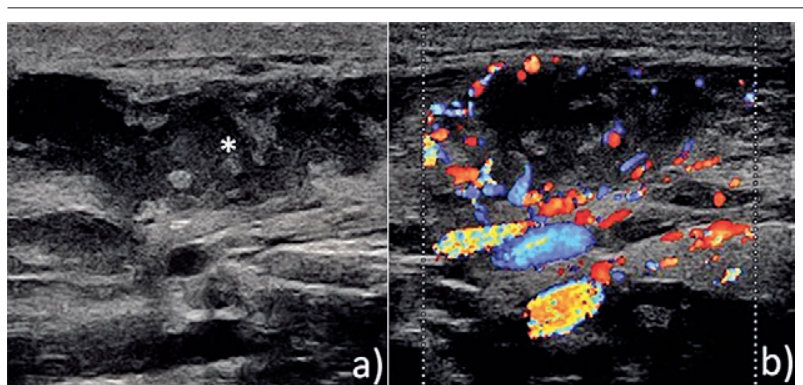

Fig 16. A 16 year old male patient with infection of the skin with Staphylococcus aureus: a) grey-scale US shows a cervical abcess (ill-defined, necrotic structure, with impure content); b) Doppler US shows no vessels inside the lesion.

Therefore, even if not specific for malignancy, this aspect should always be considered pathological [36].

Neurogenic tumors are more commonly located in the head and neck region in the carotid (related to the vagus nerve or sympathetic chain) or posterior cervical space (related to the spinal nerve or brachial plexus). Cystic areas within these tumors develop secondary to mucinous degeneration, hemorrhage or necrosis. Usually the tumors are well delineated, with a fusiform shape. When appearing in the carotid space, they are located posterior to the vessels (this feature helps in the differential diagnosis from paragangliomas which appear between the internal and external carotid arteries). Clinically, neurogenic tumors are asymptomatic and no suspicious lymphadenopathy is associated [3].

In conclusion, in cases of tumoral cervical lesions of unknown origin and etiology, ultrasonography represents the imaging method of choice, as it is able to differentiate between solid and cystic masses. The clinical examination and US appearance (location, extension, internal architecture, and vascularization) are extremely useful criteria for establishing the proper diagnosis, the optimal treatment and preoperative planning of cystic lesions in the head and neck region.

\section{Conflict of interest: none}

\section{References}

1. Băciuț M. Ecografia afecțiunilor chirurgicale maxilofaciale. Ed Sincron, Cluj-Napoca 2002: 164-176.

2. Badea RI, Băciuț M. Faringe, limbă, planşeu oral, amigdale, obraji, alte arii cervico- faciale. In: Badea RI, Dudea SM, Mircea PA, Zdrenghea D. Tratat de ultrasonografie clinică - Capul și gâtul, toracele și mediastinul, ecocardiografie și vaselor membrelor. Ed. Medicală București; 2006: 71-104.

3. Mittal, MK, Malik A, Sureka B, Thukral BB. Cystic masses of neck: A pictorial review. Indian J Radiol Imaging 2012; 22: 334-343.
4. Castelijns JA, van den Breckel MWM, Mukheji SK, Lameris JS. Ultrasound of the neck. In: Som PM, Curtin HD et al. Head and Neck Imaging - Temporal bone. Upper aerodigestive tract. Neck. Ed. Mosby 2011: 2181-2201.

5. Harnsberger H. Expert ddx Head and Neck. Ed. Amirsys, 2009.

6. Ahuja AT, King AD, King W, Metreweli C. Thyroglossal duct cyst: sonographic appearences in adults. AJNR Am J Neuroradiol 1999; 20: 579-582.

7. Anson BJ. An atlas of Human Anatomy. 2nd ed. Philadeplphia: WB Saunders, 1963.

8. Koller KK, Alamo L, Adair CF, Smirniotopoulos JG. Congenital cystic masses of the neck: radiologic-pathologic correlation. Radiographics 1999: 19: 121-146.

9. Som PM, Smoker WRK, Curtin HD, Reidenberg JS, Laitman J. Congenital lesions of the neck. In: Som PM, Curtin HD. Head and Neck Imaging - Temporal bone. Upper aerodigestive tract. Neck. Ed. Mosby 2011: 2235-2285.

10. Allard RH. The thyroglossal cyst. Head Neck Surg 1982; 5: 134-146.

11. Filston HC. Common lumps and bumps of the head and neck in infants and children. Pediatr Ann 1989; 18: 180-186.

12. Pound LA. Neck masses of congenital origin. Pediatr Clin North Am 1981; 28: 841-844.

13. Dolata J. Thyroglossal duct cyst in the mouth floor: an unusual location. Otolaryngol Head Neck Surg 1994; 110: 580-583.

14. Ahuja AT, King AD, Metreweli C. Sonographic evaluation of thyroglossal duct cysts in children. Clin Radiol 2000; 55: 770-774.

15. Ahuja AT, Wong KT, King AD, Yuen EH. Imaging for thyroglossal duct cyst: the bare essentials. Clin Radiol 2005; 60: 141-148.

16. Telander RL, Deane SA. Thyroglossal and branchial cleft cysts and sinuses. Surg Clin North Am 1977; 57: 779-791.

17. Ahuja AT, King AD, Metreweli C. Second branchial cleft cysts: variability of sonographic appearances in adult cases. AJNR Am J Neuroradiol 2000; 21: 315-319.

18. Work WP. Newer concepts of first branchial cleft defects. Laryngoscope 1972; 82: 1581-1593.

19. Work WP. Cysts and congenital lesions of the parotid gland. Otolaryngol Clin North Am 1977; 10: 339-343.

20. Bailey H. Branchial cysts and other essays on surgical subjects in the facio-cervical region. London, England: Lewis, 1929.

21. Wong KT, Lee YY, King AD, Ahuja AT. Imaging Features of Common Non-nodal Neck Masses in Children. HK J Paediatr 2008; 13: 260-266.

22. Ahuja A, Ng CF, King W, Metreweli C. Solitary cystic nodal metastasis from occult papillary carcinoma of the thyroid mimicking a branchial cyst: a potential pitfall. Clin Radiol 1998; 53: 61-63.

23. Veivers D, Dent J. Lateral cervical cysts: an Australian perspective. ANZ J Surg 2012; 82: 799-802.

24. Goyal N, Zacharia TT, Goldenberg D. Differentiation of branchial cleft cysts and malignant cystic adenopathy of pharyngeal origin. AJR Am J Roentgenol 2012; 199 : W216-W221. 
25. Som P. Cystic lesions of the neck. Postgrad Radiol 1987; 7: 211-236.

26. Zadvinskis DP, Benson MT, Kerr HH, et al. Congenital malformations of the cervicothoracic lymphatic system: embryology and pathogenesis. Radiographics 1992; 12: 1175-1189.

27. Harnsberger H. Handbook of head and neck imaging. 2nd ed. St Louis Mo: Mosby-Yearbook, 1995.

28. Emery PJ, Bailey CM, Evans JN. Cystic hygroma of the head and neck. A review of 37 cases. J Laryngol Otol 1984; 98: 613-619.

29. Faerber EN, Swartz JD. Imaging of neck masses in infants and children. Crit Rev Diag Imaging 1991; 31: 283-314.

30. Donegan JO. Congenital neck masses. In: Cummings CU, Frederick JM, Harker LA, et al. Otolaryngology Head and Neck Sugery, vol 2. St. Louis: Mosby Year Book; 1993: 1554-1565.

31. Hunter TB, Paplanus SH, Chernin MM, Coulthard SW. Dermoid cyst of the floor of the mouth. AJR Am J Roentgenol 1983; 141: 1239-1240.
32. Black EE, Leathers RD, Youngblood D. Dermoid cyst of the floor of the mouth. Oral Surg Oral Med Oral Pathol 1993; 75: 556-558.

33. Ahuja AT, Ying M. Sonographic evaluation of cervical lymph nodes. AJR Am J Roentgenol 2005; 184: 16911699.

34. Sohn YM, Kwak JY, Kim EK, Moon HJ, Kim SJ, Kim MJ. Diagnostic approach for evaluation of lymph node metastasis from thyroid cancer using ultrasound and fineneedle aspiration biopsy. AJR Am J Roentgenol 2010; 194: 38-43.

35. Landry CS, Grubbs EG, Busaidy NL, et al. Cystic lymph nodes in the lateral neck as indicators of metastatic papillary thyroid cancer. Endocr Pract 2011; 17: 240-244.

36. Ahuja AT, Ying M, Ho SY, et al. Ultrasound of malignant cervical lymph nodes. Cancer Imaging 2008; 8: 48-56.

37. Dudea SM, Lenghel M, Botar-Jid C, Vasilescu D, Duma M. Ultrasonography of superficial lymph nodes: benign vs. malignant. Med Ultrason 2012; 14: 294-306. 